\title{
REENGENHARIA, QUALIDADE TOTAL E UNIDADES DE INFORMAÇÃO.
}

\author{
Ecio Vidotti Filho \\ Plácida L. V. A. C. Santos \\ Silvana Ap. B. G. Vidotti
}

\begin{abstract}
Resumo
Uma visão generalista da Reengenharia e da Qualidade Total enfatizando a importância destas metodologias na organização de Unidades de Informação voltadas para as necessidades do cliente/ usuário contemporâneo.
\end{abstract}

Palavras-Chave

Reengenharia, Qualidade Total, Unidades de

Informação

Pautados na descoberta de Adam Smith, de que a prática de trabalho deve ser decomposta em suas tarefas mais simples e básicas, as atividades das Unidades de Informação, até a pouco tempo eram apresentadas como compartimentos estanques. Hoje, o que temos, numa era pós-industrial, é a idealização dessas Unidades de Informação como sendo constituídas em torno da idéia de reunificação de tarefas em práticas de trabalho voltadas para o cliente/ usuário.

A Reengenharia é a reunião de técnicas que possibiblitam este encaminhamento, uma vez que ela discute questões do tipo porque fazemos o que fazemos. A Reengenharia pode ser considerada como um conjunto de conceitos que devem ser adicionados ao esforço pela sobrevivência e crescimento das Unidades de Informação nesta "era da competência". Esta opção pela sobrevivência deve, contudo, passar por duas técnicas de trabalho e administração: a Reengenharia e a Qualidade Total, ou seja, pela reorganização e busca pelo melhoramento gradual e contínuo.

As estruturas tradicionais sufocam a inovação e a criatividade. A rigidez, a insensibilidade, a falta de foco no usuário, uma obsessão com a atividade ao invés do resultado, a paralisia burocrática, a falta de inovações são marcantes na estrutura tradicional de administração das Unidades de Informação, o que as torna inoperantes.

O mundo de Adam Smith é um paradigma do passado. Atualmente as atividades orientadas para a realização de tarefas são obsoletas. Hoje é necessário organizar as práticas de trabalho em torno de processos que possuam saídas de valor para o usuário do sistema.

A Reengenharia é a utilização da tecnologia objetivando modificar fundamentalmente a forma como se conduz um sistema, e não simplesmente fazê-lo funcionar de modo mais rápido. Este talvez seja o maior problema verificado com a automação dos sistemas. De um modo geral;; simplesmente se automatiza os sistemas vigentes, sem questioná-los com a profundidade necessária.

Contudo, temos que nos lembrar que a Reengenharia não se propõe a aperfeiçoar ou otimizar atividades administrativas, mas sim a orientar uma reorganização radical dos processos administrativos para a obtenção de ganhos nos indicadores de desempenho (custo, qualidade, serviços e resultados).

Isto implica, basicamente, que, se pensamos em processo, estamos nos voltando aos métodos de Reengenharia, pois ela trata basicamente de começar de novo. Todavia, se nossa preocupação está voltada para o aperfeiçoamento de atividades, estamos então nos 
referindo aos métodos de Qualidade Total, ou ao programa de TQM (Total Quality Management), sobretudo sobre o ótica clássica que conceitua a qualidade total como sendo a mobilização total dos recursos humanos para a qualidade.

Basicamente, a meta da Qualidade Total é sempre um delta acima do estágio em que nos encontramos, e isto denota claramente o processo de melhoria contínua, com a qual convivemos desde o aparecimento da raça humana.

Devemos refletir, portanto, sobre qual das técnicas apresentadas deve ser utilizada para a melhor organização das Unidades de Informação. As técnicas de Reengenharia e Qualidade Total, especificamente, apresentam diferenças radicais em seus conceitos, que devem ser consideradas e ponderadas caso a caso.

A Reengenharia se alicerça em um reprojeto radical dos processos administrativos, e praticamente exige a quebra das regras antigas. Ela não trata de consertar nada, e não é um artifício que promete melhorar a qualidade do produto ou serviço oferecido pelas Unidades de Informação. A Reengenharia é basicamente um começar de novo.

Em contraponto, temos a Qualidade Total que tem um aspecto menos radical e que pode ser apresentada como uma decorrência das técnicas de busca pela excelência utilizadas ao longo do tempo, de forma não organizada.

Os programas de Qualidade Total têm como concepção fundamental a participação maciça dos níveis operacionais, as ações de curto prazo e os objetivos incrementais. O que importa é que a atividade seja bem feita, de acordo com as especificações e com os procedimentos estabelecidos. Ao contrário, a Reengenharia deve ser implementada de modo "top-down", e o que importa é "o que fazer", com um desenho radicalmente novo do trabalho.

Diante do exposto, é importante a definição clara de quais são os objetivos da Unidade de Informação. Apenas após respondida esta questão é que poderemos dizer qual a abrangência e profundidade necessárias ao caso, ou seja, qual a radicalidade exigida. O Grau de radicalização exigido é que irá definir a técnica a ser empregada.

Se observarmos com detalhe os contornos econômicos atuais, perceberemos que tanto empresas de grande, como de pequeno porte, sendo elas de serviço ou industriais, têm que planificar suas estratégias para ultrapassar o período de uma economia industrial para a economia da informação. Até há bem pouco tempo, a melhoria na produtividade dependia do trabalho, do capital e da tecnologia. Atualmente, um dos fatores principais para desenvolver o poder competitivo e a competência é trabalhar mais, e de modo mais organizado no âmbito da informação, o que, como conseqüência, exige que os recursos informacionais sejam geridos de maneira muito mais eficaz.

Importante, neste momento, é considerarmos que as atividades de informação estão em todos os setores econômicos. Portanto a análise que os profissionais envolvidos devem fazer é a que as Unidades de Informação são, em verdade, unidades prestadoras de serviços comerciais, submetidas portanto aos mesmos valores de mercado e de competitividade que qualquer outra empresa.

Os Sistemas de Informação podem ser reconhecidos como uma interação de pessoas, máquinas, documentos, métodos e controles, estabelecidos para criar um fluxo de informações capaz de estimular as bases para a tomada de decisão nos mais diversos setores da atuação humana.

Os sistemas, todavia, não são homogêneos, nem na sua prática, nem nos seus problemas. Isto equivale dizer que, para um mesmo momento, as duas técnicas apresentadas poderão, e/ou deverão estar sendo usadas nas Unidades de Informação, visando a melhoria de seu desempenho global. Assim, setores seriam submetidos ao tratamento radical da Reengenharia, enquantos outros estariam sendo melhorados continuamente. Em um segundo momento, esta ordem seria invertida, criando um círculo de aperfeiçoamento, na busca pela excelência.

Os quadros apresentados na página ao lado ilustram as diferenças básicas entre Qualidade Total e a Reengenharia e ajudam a orientar a escolha da melhor alternativa.

Muitas panacéias tem sido prescritas na última década, e nem todas apresentaram os resultados esperados ou prometidos. O importante é ter a consciência que nenhuma solução é milagrosa, nem tampouco indolor. Nenhuma delas é rápida ou simples. 


\begin{tabular}{|c|c|c|}
\hline & Melhoria contínua & Reengenharia \\
\hline Ponto de vista & Atividades, etapas e fluxos & Processos de negócios \\
\hline Argumento & $\begin{array}{l}\text { É sempre possível fazer } \\
\text { melhor }\end{array}$ & $\begin{array}{l}\text { Ás vezes é necessário } \\
\text { começar de novo }\end{array}$ \\
\hline Papel da tecnologia & Auxiliar & Essencial \\
\hline Drive force & Bottom-up & Top-down \\
\hline Fonte do resultado & $\begin{array}{l}\text { A soma de numerosos } \\
\text { pequenos } \\
\begin{array}{l}\text { aperfeiçoamento } \\
\text { apforcos de }\end{array}\end{array}$ & $\begin{array}{l}\text { Desenho radicalmente novo } \\
\text { do trabalho }\end{array}$ \\
\hline Grau de mudança & Incremental e contínua & Ordem de grandeza \\
\hline Motivo para adoção & $\begin{array}{l}\text { Reconhecimento } \\
\text { necessidade }\end{array}$ & $\begin{array}{l}\text { Obrigatória para atingir } \\
\text { resultados esperados }\end{array}$ \\
\hline Abordagem & Evolutiva & Revolucionária \\
\hline Estratégia & $\begin{array}{l}\text { Novas soluções baseadas nos } \\
\text { processos atuais }\end{array}$ & $\begin{array}{l}\text { Questionante de todas as } \\
\text { premissas }\end{array}$ \\
\hline Esforço & Contínuo & Periódico \\
\hline Organização & Modificada & Nova estrutura \\
\hline Fonte da solução & Nível operacional & Grupo de alto nível \\
\hline Principal impacto & Como fazer & O que fazer \\
\hline Ponto de partida & Processo existente & Estaca zero \\
\hline Grau de risco & Moderado & Alto \\
\hline Habilitador principal & Controle estatístico & Tecnologia de informação \\
\hline Argumento de venda & $\begin{array}{l}\text { Exigência para não ficar de } \\
\text { fora }\end{array}$ & Diferencial competitivo \\
\hline
\end{tabular}

Fonte: (RAE, v.34, n.4,1994:28)

\section{TQM e Reengenharia: integração}

\section{Diferenças}

. Reengenharia busca mudanças radicais e ganhos ambiciosos. TQM busca mudanças incrementais;

. TQM parte do processo tal como ele é. Reengenharia parte de uma folha em branco;

. Reengenharia é implantada top to down. TQM tende a ser mais participativa;

. TQM tenta minimizar variações. Reengenharia localiza fontes de variação para criar mudanças.

\section{Similaridades}

. Ambas vêem os processos como unidade de análise;

. Tanto TQM quanto Reengenharia exigem medições;

. As duas abordagens implicam e necessitam de mudanças significativas de comportamento.

\section{Ganhos da integração}

. Maior orientação para resultados da Reengenharia compensaria a fraqueza do TQM nesse aspecto;

. Maior apoio da alta gerência à Reengenharia poderia ser capitalizado;

. experiência e conhecimento dos profissionais de TQM em relação à análise e medição de processos poderiam ser utilizados;

. ferramentas de TQM seriam úteis para entender e melhorar processos existentes no curto prazo;

- o trabalho de estabilização dos processos - via TQM - poderia ser feito após as mudanças radicais - via Reengenharia. 
Ao contrário, o trabalho é sempre difícil e sacrificante. Requer que os níveis hierárquicos gerenciais substituam as antigas práticas, com as quais existe o hábito, por outras, muitas vezes, completamente novas. Certamente, não se trata de uma tarefa que possa ser realizada através apenas de conferências motivadoras ou cartazes atraentes.

Estas proposições valem tanto para a Reengenharia quanto para a Qualidade Total, e não foram abordadas com a profundidade necessária, nem era este o propósito deste artigo. A idéia era a de fomentar a discussão, e a de apresentar estas duas ferramentas como complementares em uma organização convencional.

O fundamental é que as Unidades de Informação percebam que algo deve ser feito na busca pela excelência.

O importante é frisar que qualquer ganho em competitividade dará à Unidade de Informação um diferencial que rapidamente será percebido pelo mercado. Este ganho, difícil de ser mensurado, certamente, será extremamente significativo nesta "era da competência".

\section{BIBLIOGRAFIA}

BARROS, C.D.C. Sensibilizando para a qualidade. Rio de Janeiro : Qualitymark, 1992. 112p.

GONÇALVES, J.E.L. Reengenharia um guia de referência para o executivo. Revista de Administração de Empresas, São Paulo, v.34, n.4, p.23-30, jul./ago.1994.

HAMMER, M., CHAMPY, J. Reengenharia: revolucionando a empresa em função dos clientes, da concorrência e das grandes mudanças da gerência. Rio de Janeiro : Campus, 1994. 189p.

JURAN, J.M. Juran planejando para a qualidade. Trad. João M. Csillag, Cláudio Csillag. São Paulo : Pioneira, 1992. 394p.

LOBOS, Júlio. Reengenharia: apesar das pessoas? São Paulo : Instituto de Qualidade, 1994. 219p.

MANN, N.R. Deming: as chaves da excelência. Trad. José Carlos B. Santos. São Paulo : Makron, McGraw-Hill, 1992. 130p.

WOOD Jr., T., URDAN, F.T. Gerenciamento da qualidade total: uma revisão crítica. Revista de Administração de Empresas, São Paulo, v. 34, n.6, p.46-59, nov./dez. 1994.

\section{Ecio Vidotti Filho}

Engenheiro de Alimentos / Gerente de Produção - Especialista em Gestão da Produção.

\section{Plácida L. V. A. C. Santos}

Doutora em Semiótica e Linguística Geral; Docente de Biblioteconomia - UNESP/ Marília.

\section{Silvana Ap. B. G. Vidotti}

Mestre em Ciências da Computação; Docente de Biblioteconomia - UNESP/Marília. Grupo de Pesquisa - Novas Tecnologias em Informação.

\section{Title}

Reengineering, total quality management and information system

\section{Abstracts}

This work deals with Reengineering and Total Quality, from a management point of view, and their importance on the organization of the Information System directed to the contemporany client/user's needs.

\section{Keywords}

Reengineering - Total Quality - Information System

Apresentado no COBIBiii em agosto de 1995

Inf.Inf., Londrina, v.3, n.1, p.51-54, jan./jun. 1998 